Original Article

\title{
Long-Term Results of Modified Bentall Procedure Using Flanged Composite Aortic Prosthesis
}

\author{
Kiyoshi Tamura, MD, Hirokuni Arai, MD, Satoru Kawaguchi, MD, Satoru Makita, MD, \\ Naoto Miyagi, MD, Taiju Watanabe, MD, and Tatsuki Fujiwara, MD
}

\begin{abstract}
Purpose: We have been using the flanged composite aortic prosthesis and Carrel button technique to re-attach the coronary ostia in aortic root replacement procedures at our institution over the last twenty five years. Our objective was to evaluate the long-term results of aortic root replacement with this technique.

Methods: A total of 73 patients from January 1984 to August 2010 were included in this study. The median age was $52.7 \pm 14.4$ years (range 28-80 years). There were 48 male and 25 female patients. 44 patients $(60.3 \%)$ had annuloaortic ectasia, and 15 patients $(20.5 \%)$ had acute type A aortic dissection. Marfan syndrome was recognized in 12 patients (16.5\%).

Results: The early mortality rate was $5.5 \%(n=4)$. Causes of death were multiple organ failures in two patients and sepsis in another two patients. The actuarial survival rate was $84.2 \%$ at 5 years, $64.3 \%$ at 15 years and $51.9 \%$ at 25 years. Only one patient with aortitis needed a reoperation because of coronary pseudoaneurysm after 23 years from the previous operation. Conclusion: This modified Bentall procedure is reliable and safe, with superior long-term survival and a low rate of aortic reoperation.
\end{abstract}

Keywords: bentall procedure, aortic root replacement, carrel button technique

\section{Introduction}

The surgical reconstruction of the aortic root with a valved composite graft was first reported by Bentall and DeBono. ${ }^{1)}$ This original Bentall method employed in site circumferential suture lines around the coronary ostia and complete aortic wraparound to control bleeding. Tension within the perigraft space conveyed the surgical risk of coronary separation, false aneurysm formation, and reoperation. ${ }^{2,3)}$ To avoid this problem, Cabrol et al. adopted interposition Dacron conduits to the coronary ostia with the new risk of graft thrombosis. ${ }^{4)}$ Additionally, compos-

Department of Cardiovascular Surgery, Tokyo Medical and Dental University, Tokyo, Japan

Received: February 24, 2012; Accepted: March 16, 2012 Corresponding author: Hirokuni Arai, MD. Department of Cardiovascular Surgery, Tokyo Medical and Dental University, 1-5-45 Yushima, Bunkyo-ku, Tokyo 113-8519, Japan

Email: hiro.cvsg@tmd.ac.jp

(C)2012 The Editorial Committee of Annals of Thoracic and Cardiovascular Surgery. All rights reserved. ite aortic root replacement with direct coronary artery implantation was reported with excellent results. ${ }^{5-7)}$

In our institution, we have selected the flanged composite aortic prosthesis and Carrel button technique to re-attach the coronary ostia for the aortic root replacement since 1984, and Suzuki et al. reported modified Bentall method for aortitis previously. ${ }^{8)}$ We sought to evaluate the longterm results of aortic root replacement with this technique.

\section{Materials and Methods}

\section{Patient characteristics}

Between January 1984 and August 2010, 73 patients (48 males, 25 females; mean age $52.7 \pm 14.4$ years $52.7 \pm$ 14.4 years; range 28 to 80 years) underwent aortic root replacement with the valve composite flanged graft and Carrel button technique to re-attach the coronary ostia. Medical records were reviewed retrospectively for patient demographics, preoperative symptoms, preoperative echocardiographic findings, operative procedures, and survival. Follow up was obtained by office visits and/or 
telephone interviews. Follow-up was complete in 68 patients (93.2\%). Average follow-up length was $83.5 \pm 85.0$ months (range 2 to 306 months). The study protocol was approved by the ethics broad of our hospital. All patients were informed about the procedure and provided written confirmation for the operation.

Indications for surgery were annuloaortic ectasia (AAE) in 44 patients $(60.3 \%$, eight patients with Marfan syndrome), acute type A aortic dissection in 15 patients (20.5\%, four patients with Marfan syndrome), aortitis in 11 patients (15.1\%), coronary pseudoaneurysm after original Bentall procedure in two patients (2.7\%), and lues in one patient (1.4\%). Marfan syndrome was present in 12 patients $(16.5 \%)$. The preoperative data are given in Table 1.

\section{Surgical technique}

The cardiopulmonary bypass was instituted with ascending aortic cannulation and bicaval drainage. Femoral cannulation was performed in patients with aortic dissection, ascending aorta aneurysm extending to the aortic arch, and emergency status and axillary artery for recent cases. Anterograde or retrograde cold cardioplegia was applied for the myocardial protection. Deep hypothermic circulatory arrest with retrograde cerebral perfusion $\left(20^{\circ} \mathrm{C}\right)$ was applied in patients requiring concomitant transverse arch replacement.

After cross-clamping of the ascending aorta, the aorta was completely transected at the sinotubular junction and distally $2 \mathrm{~cm}$ from the cross-clamp. The aortic leaflets were not removed. We have made coronary buttons with a $1 \mathrm{~cm}$ diameter cuff of the aortic wall and directly anastomosed to the composite graft with the exclusion technique to avoid producing a pseudoaneurysm.

We made a flanged composite graft in the operating room. A flange, the segment ( $7 \mathrm{~mm}$ in length) of the proximal end of the vascular graft was made for the implantation. After we had sized the aortic annulus for the prosthetic valve, we selected the tubular graft one or two size wider than the prosthetic valve. The prosthetic valve was inserted into the graft and was fixed at the three corners to the graft with 3-0 polyester sutures at the point 7 $\mathrm{mm}$ form the end of the graft. Then, a continuous 3-0 polyester suture was performed to anastomose the sewing cuff of the prosthetic valve.

The composite valve graft was implanted by attaching the prosthetic valve ring of the handmade composite valved conduit into the aortic annulus with pledgeted horizontal mattress sutures. Then, one or two continuous 3-0 polyester sutures were performed to anastomose the flange of the handmade composite valved conduit. The coronary buttons were anastomosed to the composite valve graft end-to-side with continuous suture used a 5-0 polyfluoridevinyl line and interrupted suture used 5-0 pledgeted polyfluoridevinyl line.

The distal anastomosis was performed to the transected aorta with a continuous 4-0 polyfluoridevinyl suture.

For arch replacement, total circulatory arrest with retro and/or anterograde cerebral perfusion was performed before coronary reconstruction. Concomitant procedures were summarized in Table $\mathbf{1}$.

\section{Statistical methods}

Continuous data are expressed as mean \pm SD with ranges when appropriate. Comparisons between two categories variables were made using the Student's $t$ test for continuous variables. Otherwise, nonparametric MannWhitney $U$ test was used. Parametric data were examined with contingency tables, with Fisher's exact test, as appropriate. The follow-up survival was assessed using the Kaplan-Meier survival curve and log rank test. Differences were considered significant at $p<0.05$. Statistical analysis was performed with StatView for Windows version 6.0 (SAS Institute Inc, Cary, NC).

\section{Results}

\section{Mortality}

The early mortality was $5.5 \%$ (four patients). Causes of death were multiple organ failure in two patients, and sepsis, in another two patients.

There have been 12 late deaths (16.5\%). The causes of late deaths were three cerebral vascular accidents, three sepsis, two sudden deaths, two heart failures, one colon carcinoma and one unknown. The actuarial survival rate was $84.2 \%$ at 5 years, $64.3 \%$ at 15 years, and $51.9 \%$ at 25 years (Fig. 1).

There have been five cardiac deaths $(6.8 \%)$. The actuarial survival rate from cardiac death was $96.9 \%$ at 5 years, $88.9 \%$ at 15 years, and $80.8 \%$ at 25 years (Fig. 2).

\section{Postoperative complications}

Postoperative complications were summarized in Table 1. Four patients (5.5\%) required re-thoracotomy for excessive bleeding. Two patients (2.7\%) suffered low cardiac output syndrome (LOS) and required percutaneous cardio-pulmonary assist system (PCPS). 22 patients (30.1\%) had respiratory failure requiring prolong ventilation and five of them required tracheotomy. Six patients 
Table 1 Demographic characteristics of all patients

\begin{tabular}{|c|c|}
\hline Preoperative & Number (\%) \\
\hline Patient numbers & 73 \\
\hline Male & $48(65.8 \%)$ \\
\hline Mean age & $52.7 \pm 14.4$ \\
\hline Mean NYHA function class & $2.3 \pm 1.1$ \\
\hline \multicolumn{2}{|l|}{ Risk factors } \\
\hline Hypertention & $25(34.2 \%)$ \\
\hline Coronary artery disease & $18(24.7 \%)$ \\
\hline Cerebrovascular disease & $9(12.3 \%)$ \\
\hline Low ejection fraction $(<40 \%)$ & $5(6.8 \%)$ \\
\hline Diabetes mellitus & $3(4.1 \%)$ \\
\hline Chronic obstructive pulmonary disease & $3(4.1 \%)$ \\
\hline Renal failure (hemodialysis or Cre $>2.0 \mathrm{mg} / \mathrm{dl}$ ) & $2(2.7 \%)$ \\
\hline Marfan syndrome & $12(16.5 \%)$ \\
\hline \multicolumn{2}{|l|}{ Indications for surgery } \\
\hline Annuloaortic ectasia (+ Marfan syndrome) & $44(60.3 \%)(8,11.0 \%)$ \\
\hline Aortic dissection (+ Marfan syndrome) & $15(20.5 \%)(4,5.4 \%)$ \\
\hline Aortitis & $11(15.1 \%)$ \\
\hline Pseudoaneurysm after Bentall procedure & $2(2.7 \%)$ \\
\hline Lues & $1(1.4 \%)$ \\
\hline \multicolumn{2}{|l|}{ Intraoperative } \\
\hline Previous heart surgery & $6(8.2 \%)$ \\
\hline Emergency & $11(15.1 \%)$ \\
\hline \multicolumn{2}{|l|}{ Valve type } \\
\hline Mechanical & $63(86.3 \%)$ \\
\hline Biologic & $10(13.7 \%)$ \\
\hline \multicolumn{2}{|l|}{ Concomitant procedures } \\
\hline Coronary arterial bypass grafting & $18(24.7 \%)$ \\
\hline Total arch graft replacement & $6(8.2 \%)$ \\
\hline Hemiarch graft replacement & $2(2.7 \%)$ \\
\hline Mitral valve plasty & $2(2.7 \%)$ \\
\hline Mitral valve replacement & $2(2.7 \%)$ \\
\hline Tricuspid valve annuloplasty & $1(1.4 \%)$ \\
\hline \multicolumn{2}{|l|}{ Postoperative } \\
\hline Hospital death & $4(5.5 \%)$ \\
\hline Bleeding (rethoracotomy) & $4(5.5 \%)$ \\
\hline \multicolumn{2}{|l|}{ Cardiac } \\
\hline Low output syndrome requiring IABP & $8(11.0 \%)$ \\
\hline Low output syndrome requiring PCPS & $2(2.7 \%)$ \\
\hline \multicolumn{2}{|l|}{ Neurologic } \\
\hline Cerebral infarction & $6(8.2 \%)$ \\
\hline \multicolumn{2}{|l|}{ Respiratory } \\
\hline Prolonged ventilation ( $>48 \mathrm{hr}$ ) & $22(30.1 \%)$ \\
\hline Tracheotomy & $5(6.8 \%)$ \\
\hline \multicolumn{2}{|l|}{ Renal } \\
\hline Requiring dialysis & $7(9.6 \%)$ \\
\hline \multicolumn{2}{|l|}{ Infection } \\
\hline Sepsis & $2(2.7 \%)$ \\
\hline Mediastinitis & $3(4.1 \%)$ \\
\hline
\end{tabular}

NYHA: New York Heart Association; IABP: intra-aortic balloon pumping; PCPS: percutaneous cardio-pulmonary assist system

$(8.2 \%)$ had cerebrovascular accident. Seven patients $(9.6 \%)$ required temporal renal support for acute renal failure. Three patients $(4.1 \%)$ suffered mediastinitis and required omental pedicle flap.

No patients had anticoagulant-related hemorrhage, valve thrombosis, and coronary event. One patient with aortitis had coronary pseudoaneurysm and reoperation at
23 years. Freedom from operations was $100 \%$ at 5 years, $100 \%$ at 15 years, and $66.7 \%$ at 25 years (Fig. 3).

\section{Discussion}

We have undertaken the flanged composite aortic prosthesis and Carrel button technique to reattach the 


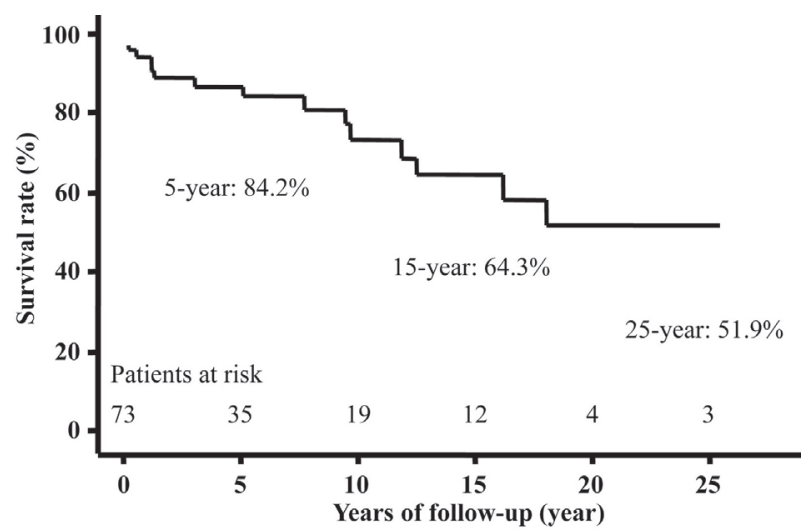

Fig. 1 Actuarial survival rate from all cause death.

coronary ostia for 73 patients over twenty five years. The most important finding in this study is that the flanged composite aortic prosthesis and Carrel button technique to reattach the coronary ostia are feasible and excellent long-term results can be achieved as other studies. $\left.{ }^{9}, 10\right)$

We believed that this technique has some advantages. The flanged part of vascular graft, as a strip over the proximal anastomosis, was used to attach to the aortic annulus by pledgeted mattress sutures. This decreases any bleeding problems from the proximal anastomosis and additional sutures for hemostasis can be easily applied for this flanged part.

Because Cooly low porosity grafts were used until 1993 in our series, there were many postoperative complications (Table 1). Perioperative bleeding tended to get much with those grafts, and caused a lot of blood transfusion and cardiac instability. Postoperative complications decreased from 1995 because of using other grafts. Then, cardiovascular accidents were much for late death causes in the present study. It was thought that Marfan syndrome and aortitis were about $1 / 3$ in all patients (23/76).

Another advantage of Carrel button technique is the method decreasing risk of new graft thrombosis. The interposed coronary graft technique, as Cabrol technique, ${ }^{4)}$ had the new risk of graft thrombosis. Although coronary stenosis after a Bentall procedure is uncommon, occurring in less than $2 \%$ of patients, the main concern with the Cabrol technique is maintaining the patency of the Dacron interposition grafts. ${ }^{11)}$ However, Knight et al. ${ }^{12)}$ reported that $14 \%$ of the Dacron interposition graft stenosis were observed in patients undergoing a Cabrol procedure. No patients had new coronary thrombosis during the course in this present study, and Carrel button technique might be more useful and safer method.

Though the incidences of pseudoaneurysm with the

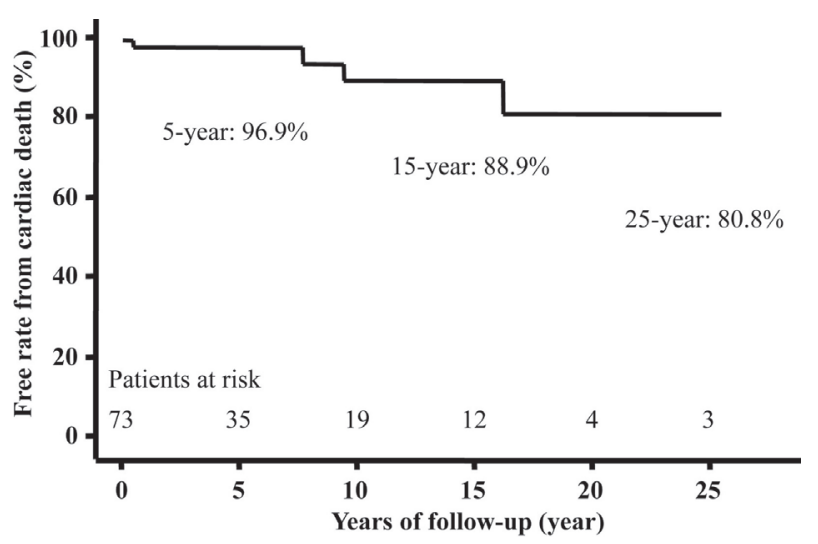

Fig. 2 Actuarial free rate from cardiac death.

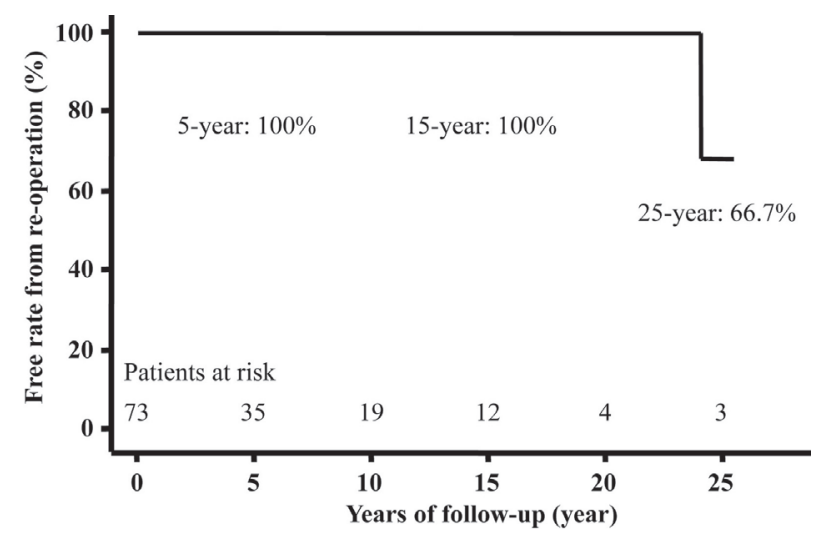

Fig. 3 Actuarial free rate from reoperation.

button technique were reported between $3.1 \%$ and $9 \%$ in other series, ${ }^{3,13)}$ only one patient $(1.3 \%)$ had coronary pseudoaneurysm formation in our study. We do some kinds things to avoid coronary pseudoaneurysm. The one is to reduce the remnants of the aortic wall in the coronary button as much as possible, the other is to anastomose continuous suture used 5-0 polyfluoridevinyl line and interrupted suture used 5-0 pledgeted polyfluoridevinyl line. Using these procedures makes it less likely to pseudoaneurysm formation and excessive bleeding. Separately interposed coronary graft technique was reported to less coronary pseudoaneurysm in other studies, ${ }^{10)}$ however, there were concerns related to the long-term patency of these grafts and increased number of coronary events. The button technique is simple anastomosis and reliable to shirk coronary events.

In an attempt to avoid anticoagulation in this relatively young patient population, Sarsam and Yacob ${ }^{14)}$ and David and Feindel ${ }^{15)}$ have described valve-preserving aortic root reconstruction techniques. And David et al reported excellent results. ${ }^{16)}$ However, these techniques had potentially 
limiting their durability and technical difficulty. By the way, composite valve conduit reconstruction, especially the Carrel button technique, is a simple procedure, which resulted in a more durable result. Savunen et al. ${ }^{17)}$ reported a $3 \%$ early mortality in 100 patients undergoing a modified Bentall procedure with no anastomotic problems in the follow-up period. Eigin et al. ${ }^{18)}$ reported a significantly reduced reoperative rate and better survival in patients undergoing the "button Bentall" procedure. Svensson et al. ${ }^{19)}$ had no reoperation in 67 patients at intermediate-term follow-up. In our study, the flanged composite aortic prosthesis and Carrel button technique to reattach the coronary ostia resulted in excellent durability and long-term mortality.

The results of this study should be interpreted in the light of certain limitations. Firstly, ours is a retrospective study. Secondly, the present study was a single-center experience, and as a result, it was limited by the relatively small number of patients included. Despite these limitations, our study provides the long-term outcomes in the patient underwent aortic root replacement with the valve composite flanged graft and Carrel button technique to reattach the coronary ostia.

\section{Conclusion}

This study shows that aortic root replacement with the valve composite flanged graft and Carrel button technique to reattach the coronary ostia is low mortality and morbidity for up to twenty years. This technique is feasible as one of many modifications of the aortic root replacement.

\section{Disclosure Statement}

The authors disclose no conflict of interest and transfer all copyright ownership of the article to the publisher.

\section{References}

1) Bentall $\mathrm{H}$, De Bono A. A technique for complete replacement of the ascending aorta. Thorax 1968; 23: 338-9.

2) Marvasti MA, Parker FB Jr., Randall PA, et al. Composite graft replacement of the ascending aorta and aortic valve. Late follow-up with intra-arterial digital subtraction angiography. J Thorac Cardiovasc Surg 1998; 95: 924-8.

3) Kouchoukos NT, Wareing TH, Murphy SF, et al. Sixteen-year experience with aortic root replacement. Results of 172 operations. Ann Surg 1991; 214: 308-18; discussion 318-20.
4) Cabrol C, Pavie A, Gandjbakhch I, et al. Complete replacement of the ascending aorta with reimplantation of the coronary arteries: new surgical approach. J Thorac Cardiovasc Surg 1981; 81: 309-15.

5) Miller DC, Stinson EB, Oyer PE, et al. Concomitant resection of ascending aortic aneurysm and replacement of the aortic valve: operative and long-term results with "conventional" techniques in ninety patients. J Thorac Cardiovasc Surg 1980; 79: 388-401.

6) Svensson LG, Crawford ES, Hess KR, et al. Composite valve graft replacement of the proximal aorta: comparison of techniques in 348 patients. Ann Thorac Surg 1992; 54: 427-37; discussion 438-9.

7) Svensson LG. Approach for insertion of aortic composite valve grafts. Ann Thorac Surg 1992; 54: 376-8.

8) Suzuki A, Amano J, Tanaka H, et al. Surgical consideration of aortitis involving the aortic root. Circulation 1989; 80: I222-32.

9) Zehr KJ, Orszulak TA, Mullany CJ, et al. Surgery for aneurysms of the aortic root: a 30-year experience. sCirculation 2004; 110: 1364-71.

10) Hirasawa $Y$, Aomi $S$, Saito $S$, et al. Long-term results of modified Bentall procedure using flanged composite aortic prosthesis and separately interposed coronary graft technique. Interact Cardiovasc Thorac Surg 2006; 5: 574-7.

11) Witzenbichler B, Schwimmbeck P, Schultheiss HP. Images in cardiovascular medicine. Myocardial infarction caused by occlusion of Cabrol conduit graft. Circulation 2005; 112: e79-80.

12) Knight J, Baumüller S, Kurtcuoglu V, et al. Long-term follow-up, computed tomography, and computational fluid dynamics of the Cabrol procedure. J Thorac Cardiovasc Surg 2010; 139: 1602-8.

13) Yakut C. A new modified Bentall procedure: the flanged technique. Ann Thorac Surg 2001; 71: 2050-2.

14) Sarsam MA, Yacoub M. Remodeling of the aortic valve anulus. J Thorac Cardiovasc Surg 1993; 105: 435-8.

15) David TE, Feindel CM. An aortic valve-sparing operation for patients with aortic incompetence and aneurysm of the ascending aorta. J Thorac Cardiovasc Surg 1992; 103: 617-21; discussion 622.

16) David TE, Maganti M, Armstrong S. Aortic root aneurysm: principles of repair and long-term follow-up. $\mathrm{J}$ Thorac Cardiovasc Surg 2010; 140: S14-9; discussion S45-51.

17) Savunen T, Inberg M, Niinikoski J, et al. Composite graft in annulo-aortic ectasia. Nineteen years' experience without graft inclusion. Eur J Cardiothorac Surg 1996; 10: 428-32.

18) Ergin MA, Spielvogel D, Apaydin A, et al. Surgical treatment of the dilated ascending aorta: when and how? Ann Thorac Surg 1999; 67: 1834-9; discussion 1853-6.

19) Svensson LG, Longoria J, Kimmel WA, et al. Management of aortic valve disease during aortic surgery. Ann Thorac Surg 2000; 69: 778-83; discussion 783-4. 